\title{
Market Led Industrialization and Globalization
}

\author{
Jeffrey Sachs \\ Harvard University \\ Xiaokai Yang \\ Monash University
}

\begin{abstract}
The paper introduces asymmetric production conditions between firms and asymmetric transaction conditions between countries into the Murphy-ShleiferVishny model of industrialization. It explores a general equilibrium mechanism that generates circular causation loop that each firm's profitability and its decision of involvement in a network of industrial linkages is determined by the size of the network, while the network size is in turn determined by all firms' decisions of participation. It shows that the very function of the market is to network relevant self-interested decision-makers and to utilize the network effects of industrialization, though this function is not perfect. Hence, market led industrialization will gradually spread until the whole world economy is integrated in a single network of trade and industrial linkages as trading efficiency is improved. This paper devises a new approach to specifying zero profit condition for a marginal modern firm, while keeping original feedback loop between positive profit and the extent of the market of the MSV model. Hence, this new method and the trade off between economies of scale and transaction costs can be used to endogenize the number of modern sectors, thereby increasing applicability of this type of models.
\end{abstract}

- JEL Classifications: D30, F10, O10

- Key Words: income distribution, division of labor, dual structure, economic development, trade pattern, economies of scale, network effect of industrial linkage.

\footnotetext{
*Corresponding address: Xiaokai Yang, Department of Economics, Monash University, Clayton, Vic. Australia 3800, Tel: +613-9905-2448, Fax: +613-9905-5499, E-mail: xiaokai.yang@buseco.monash.edu.au, Jeffrey Sachs, Center for International Development, Harvard University, 79 J.F. Kennedy Street, Cambridge, MA 02138, USA, Tel: +617-495-4112, E-mail: jeffrey_sachs@ harvard.edu. (C2002-Center for International Economics, Sejong Institution, All Rights Reserved.
} 


\section{Introduction}

The purpose of the paper is threefold. First, it formalizes one branch of high development economics which describes industrialization as a market led gradual spreading process. Second, it investigates effects of transaction conditions, which are affected by geography, institutions, and transportation and communication technology, on gradual spread of industrialization. Finally, this paper devises a new method to handle the Murphy-Shleifer-Vishny (MSV) model (1989). This new method will extend applicability of this model to the analysis of many trade and development phenomena. Let us motivate the three tasks one by one.

Since the end of the 1980s, many general equilibrium models with increasing returns have been developed to formalize what is called by Krugman (1995) "high development economics." There are two different views in high development economics. One is referred to as the theory of big push and balanced industrialization, represented by Rosenstein-Rodan (1943) and Nurkse (1952). The other is referred to as the theory of unbalanced industrialization, represented by Fleming (1954) and Hirschman (1958). When economists were not familiar with technical substance of general equilibrium models, they can only use vague words to address general equilibrium phenomena, such as circular causation, interdependent decisions in different industries, pecuniary externality of industrial linkages, and so on.

In essence, Rosenstein-Rodans idea (1943) about big push industrialization is to advocate for state led industrialization because of coordination failure in exploiting network effects of industrial linkages in a decentralized market. This idea is formalized by the MSV model with the feedback loop between the extent of the market and economies of scale that can be exploited. Hirschman's idea (1958) about pecuniary externality of industrial linkages relates more or less to market led industrialization since the network effects of industrial linkages are pecuniary (which can be exploited by the price system). Term "balanced vs. unbalanced industrialization" may be misleading. Unbalanced industrialization strategy may be associated with specialization of a country in a particular sector and international division of labor between countries. Hence, from a view of the world market, such a strategy is a balanced industrialization strategy, although it is not balanced within a single country (Sheahan, 1958). We shall extend the MSV model to formalize Hirschman's idea on market led spread of industrialization.

Casual observation indicates that industrialization was gradually spread from 
the UK to Netherlands and France, then to Germany and other Central and Northern European countries, and finally reached Southern Europe and the rest of the world. In Asia, industrialization started in Japan in the end of $19^{\text {th }}$ century, then gradually spread to Hong Kong, Singapore, Taiwan, South Korea, and other Asian countries.

The observed spread of industrialization is affected by transaction conditions. There are three major determinants of transaction conditions: institutions, geography, and technology. Industrialization started in the island countries, then spread to coastal regions of the continent, then to hinterland countries. It was so in Europe in the $18^{\text {th }}$ and $19^{\text {th }}$ century (the UK is an island country, Netherlands and France are in coastal region, and Germany and other central European countries are hinterland countries) and in Asia in the $19^{\text {th }}$ and $20^{\text {th }}$ century (Japan and Taiwan are island countries, Singapore, Hong Kong, and South Korea are in coastal region, China and India are continental countries with vast hinterland areas).

Effects of institutions on transaction conditions and thereby on economic development have been investigated by North (1981), North and Weingast (1989), Mokyr (1990, 1993), and others. Gallup and Sachs (1998) provide empirical evidence for effects of geography on transportation conditions and thereby on economic development. They use cross country data to show that the population share of coast region and distance from the major international market have very significant impact on per capital income.

Institutions and geography are not independent of each other. Baechler (1976, pp. 78-80) notes that geographical conditions of Europe created a variety of polity and rivalry between hostile sovereignties within the same cultural whole in Europe, which encouraged many different institutional experiments. A particular geographical condition ensured that Britain could avoid war with other countries at low defense expenses and had transportation advantage for trade. Pursuit of riches was legitimated under the prevailing ideology, so that talents were diverted from military, religious, and bureaucratic careers to business activities prior to and during the Industrial Revolution.

In the paper, we will introduce asymmetric production conditions between firms and asymmetric transaction conditions between countries into the MSV model of industrialization (1989). In the MSV model market prices are determined by the zero profit condition in the traditional sector with constant returns to scale technology and therefore its algebra is easy to manage. The feedback loops 
between the extent of the market, dividend earnings, economies of scale that can be exploited, and quantities demanded nicely formalize a general equilibrium mechanism that can talk to circular causation, network effects of industrial linkages, and interdependence between production and market conditions and decisions in different sectors, which concerned high development economists.

There is some technical difficulty of this kind of models that restricts its broad application. The price of the goods produced by the active modern sectors is a constant, determined by the zero profit condition of cottage firms. This paralyzes the functioning of the price system to transmit information of the production condition of the modern firms to consumers. Hence, the number of modern sectors cannot be endogenized by using the zero profit condition. Kelly (1997) introduces the trade off between economies of scale and transaction costs into the MSV model to endogenize the number of modern sectors. Because of zero profit condition, consumers utility does not go up as the number of modern sectors increases in that model. If the assumption of positive profit is maintained to keep the flavor of feedback loop between the extent of the market and economies of scale that can be exploited, the model is short of one equation to endogenize the number of modern sectors.

In this paper, we develop an analytical approach to specifying a zero profit condition for a marginal modern firm, while keeping positive profit for other active modern firms. Following Kelly, we specify the trade off between economies of scale and transaction costs to endogenize the numbers of active modern and traditional firms. This approach keeps the original flavor of the MSV model: interdependence between the extent of the market and economies of scale, and compatibility between price taking and global economies of scale. A key ingredient that makes this approach work is asymmetry of production conditions between different modern firms and asymmetry of transaction conditions between countries. This new approach to handling the MSV model will make this model more applicable to the analysis of many problems in economic development, trade, urbanization, and industrial organization.

The introduction of the trade off between economies of scale that can be exploited and transaction costs can accommodate empirical evidence that is at odds with the MSV model. The MSV model predicts that a large population size has a positive effect on industrialization. But the first country that was industrialized (UK) was not the most populous country (which was China). Empirical evidence provided in National Research Council (1986) and Dasgupta (1995) 
rejects this type of scale effect. Murphy, Shleifer, and Vishny (1989) suggest introducing transaction costs to counteract the scale effect. Our model will substantiate their idea and show that there exists substitution between population size and trading efficiency in promoting industrialization and economic development and that a large country can be locked in the development trap if its transaction efficiency is low.

In section 2, equilibrium and comparative statics of the extended MSV model are solved. We then extend the model to the case with many countries to endogenize a dual structure between integrated developed world and autarkic less developed world in section 3. In addition, a dynamic version of the model is considered. The final section concludes the paper.

\section{An Extended Murphy-Shleifer-Vishny Model of Industrialization Consumers' Decisions}

Following MSV, we assume that the set of consumption goods produced by the industrial sector is a continuum with mass $m$. Each consumer-worker-owner has a Cobb-Douglas-CES utility function. Her decision problem is:

$$
\operatorname{Max}: U=\left[\int_{0}^{m} x(j)^{\rho} \mathrm{d} j\right]^{\alpha \rho} z^{1-\alpha} \text {, s.t. } \int_{0}^{m} p(j) x(j) d j+p_{\mathrm{z}} z=I=(\pi+w) .
$$

where $j \in[0, m]$ is an index of industrial goods, $x(j)$ is the quantity of good $\mathrm{j}$ consumed, $p(j)$ is the price of $\operatorname{good} j, z$ is the quantity of agricultural good consumed, $p_{\mathrm{z}}$ is the price of the agricultural good. Each consumer endowed with one unit of labor has income $I$ which consists of dividend earning $\pi$ and wage income $w$. Labor is assumed to be the numeraire, so that $w=1$. Ownership of all firms is equally shared by all consumers. Later, we shall show that in equilibrium $p(j)=1$ for all $j$. Hence, the optimum quantity demanded of good $j$ is the same for all $j$. Using the symmetry, the solution to the problem (1) can be found as follows.

$$
x=\alpha I / m, z=(1-\alpha) I / p_{z}
$$

The total market demand is:

$$
X^{d}=\alpha I L / m=\alpha(\Pi+L) / m, Z^{d}=(1-\alpha)(\Pi+L) / p_{z}, \Pi=\pi L
$$


where $\Pi$ is total dividend earning which is equal to total profit. We now consider the production of $z$. The production function of $z$ is

$$
Z=\theta L_{z}
$$

where $\theta$ is an agricultural productivity parameter, $L_{z}$ is the amount of labor allocated to the production of $z$. The equilibrium price of good $z$ is thus $p_{z}=1 / \theta$ and the equilibrium quantity of good $z$ consumed and produced is then $Z=(1-$ $\alpha) \theta(\Pi+L)$.

\section{A. Production of Industrial Goods}

For each industrial good, there are two available technologies. The modern one exhibits economies of scale and the traditional one is $x_{h}=L_{h x}, x_{h}$ is the output of a traditional (cottage or handcraft) sector and $L_{h x}$ is the amount of labor allocated to this sector. Because of the existence of the traditional technology, the labor prices of all industrial goods are always 1 , so that the quantity demanded is the same for all industrial goods. The production function of the modern sector producing good $j$ is

$$
x_{j}=\left(L_{j}-F_{j}\right) / b, F_{0}=\delta, F_{j}=\gamma j>\delta \text { for } j \in(0, m] .
$$

where $x_{j}$ is the quantity supplied, $L_{j}$ is the amount of labor allocated to the production of the industrial good, and $F_{j}$ is the fixed production cost of good $j$. We assume that the fixed cost differs across modern sectors and that the industrial goods are indexed according to their fixed costs. Industrial good 0 has the smallest fixed cost $\delta$, which is a very small positive number, industrial good $m$ has the largest fixed cost $\gamma m$, and for $j \in(0, m], F_{\mathrm{j}}=\gamma j \in(\delta, \gamma m]$. Here, $\gamma$ can be considered as a general production condition parameter. As $\gamma$ decreases, the fixed cost for any modern sector $\mathrm{j}$ decreases. Also, $F_{j}$ can be interpreted as the degree of capital intensity. A large value of $F_{j}$ implies that the modern sector $j$ needs a high investment in fixed cost before a positive output can be produced. Hence, index $j$ can be considered as an index of capital intensity of the modern sectors. Here, we assume that there is only one active or potential traditional firm for each sector since the number of traditional firms is not essential for our results. This assumption implies that subscript $j$ can represent an industrial sector, an active traditional firm, or an active modern firm when no confusion is caused. For each 
sector, either a traditional firm or a modern firm is active. Without lose of generality, we use the symmetry to assume that the continuum set of modern firms is $[0, n]$ and that of traditional firms is $[n, m]$, where the equilibrium value of $n \in[0$, $m$ ] is endogenously determined.

We assume further that there is a variable transaction cost for each modern firm. The transaction condition differs across countries. The transaction cost incurred to a modern firm in country $i$ is

$$
C_{i}=c_{i} x_{j}, c_{0}=s, c_{i}=\mu i>s \text { for } i \in(0, M]
$$

where $i \in[0, M]$ is an index of countries, $s$, a very small positive number, is the transaction cost coefficient for country 0 , and $x_{j}$ is the output level of modern sector $j$ which is the same in any country and in any sector as we have shown. The set of countries is a continuum. The specification implies that two factors determine the transaction cost coefficient: a general transaction condition $\mu$ and country specific transaction condition represented by index $i$. for a larger $i$, the transaction cost coefficient $c_{\mathrm{i}}$ is larger. ${ }^{1}$ A country's geographical condition and institutional and cultural tradition determines its ranking index $i$. For any given $i$, the transaction cost coefficient $c_{\mathrm{i}}$ decreases as $\mu$ decreases. A decrease in $\mu$ can be caused by worldwide changes in transportation technology or institutions. For instance, innovation of automobile manufacturing technology reduces transportation cost worldwide. Institution of World Trade Organization reduces trade barriers and related transaction costs.

We may consider country 0 as the country with the best transaction condition and country $M$ as the country with the worst transaction condition. The country specific transaction cost is affected by country specific geographical and institutional conditions. For instance, Britain as an island country has very favorable transportation condition for international trade via seas. Its common law tradition and constitutional order established in 1688 are conducive to reduction of transaction costs.

The transaction cost is an iceberg transaction cost, which implies that for each unit of output, the seller can receive only revenue 1-c. You may consider that each unit of good sold melts on the way from the seller to the buyer, so that the seller

\footnotetext{
${ }^{1}$ We take the transaction cost coefficient as a black box. The literature of endogenous transaction cost has opened the black box and shown that moral hazard, adverse selection, and other opportunism may generate endogenous transaction costs. See Milgrom and Roberts (1992), Hart (1995), and Holmstrom and Roberts (1998).
} 
can only make revenue of 1-c from the sale. Hence, the total revenue received by the seller is $(1-c) x_{j}$ instead of $x_{j}$. The coefficient $c$ can be considered as a tax rate when all tax revenue is wasted. The iceberg transaction cost is specified in many recent models with the trade off between economies of scale and transaction costs (see Krugman and Venebles, 1995 for instance) since it can ensure tractability of comparative statics of general equilibrium by avoiding notoriously formidable index set of origins and destinations of trade flows. Trade of goods produced by cottage firms involves no transaction costs except that international trade of the goods may involve infinitesimally positive transaction cost, compared to domestic trade. The assumption is justified by the following facts. Productivity and prices of goods produced by cottage firms are independent of the size of the firm and thereby independent of the extent of the market. Hence, each cottage firm can avoid transaction cost by locating next to the buyer. But international trade involves visa cost and other costs that are absent in domestic trade. It will be clear later that with the assumptions a country never participate in international trade if all modern firms are inactive in equilibrium.

The profit of firm $j$ in country $i$ is

$$
\pi_{i j}=x_{j}-L_{J}-c_{i} x_{j}=(1-\mu i-b) x_{j}-\gamma j
$$

where $x_{j}=X^{d} /\left(1-c_{i}\right)$ is determined by the market clearing condition and demand function given in (2). Total dividend earning is equal to total profit of $n$ active modern firms.

$$
\Pi=\int_{0}^{n} \pi_{i j} d j
$$

where $n \in[0, m]$ is endogenously determined. Plugging this expression for total dividend earning into (2), total market demand for the good produced by firm $j$ and this firm's output are, respectively:

$$
X^{d}=\alpha(\Pi+L) / m \text { and } x_{j}=X^{d} /\left(1-c_{i}\right)
$$

where the number of all industrial goods is $m$, the number of active traditional sectors is $m n$. (6)-(8) nicely captures the feedback loop between income, demand, and production conditions. It also captures the idea of big push industrialization. If the transaction cost is 0 , as more modern firms operate ( $n$ increases), dividend 
earning and income increases, demand increases, which makes more modern firms profitable. Hence, as the population size reaches a threshold level, the equilibrium number of modern sectors, $n$, jumps from 0 to its upper bound $m$ (see Murphy, Shleifer, and Vishny, 1989). But in our model, transaction costs counteract the positive feedback between the extent of the market and economies of scale that can be exploited, so that industrialization may occur gradually as the transaction conditions are improved.

Inserting (8) into (6), then inserting the resulting expression into (7), we can conduct integration and then express total income $\Pi+L$ as a function of $n$.

$$
\Pi+L=\left(L-0.5 \gamma n^{2}\right) m /\{m-\alpha n[1-b /(1-\mu i)]\}
$$

where $L-0.5 \gamma n^{2}>0$ and $m-\alpha n[1-b /(1-\mu i)]>0$ are required by positive income. We now consider the zero profit condition for the most capital intensive active modern sector $n$. Letting $j$ equal $n$ in (6) and $\pi_{n}=0$, we get the zero profit condition, $\pi_{n}=(1-b-\mu i) x_{J}-\gamma n=0$. Inserting the demand function, given in (8), into the zero profit condition for the marginal active modern firm generates another expression of $\Pi+L$.

$$
\Pi+L=\gamma m n(1-\mu i) /(1-b-\mu i) \alpha
$$

where $1-b-\mu i>0$ is required by positive income. (9) and (10) together give the equilibrium number of active modern firms $n$ as a function of parameters $\gamma, \mu, L$, $b, i, \alpha^{2}$

$$
f(n, \gamma, \mu, L, b, i, \alpha)=A n^{2}-B n+D=0
$$

where $A \equiv 0.5 \alpha \gamma[1-b /(1-\mu i)], B \equiv m \gamma, D \equiv \alpha L[1-b /(1-\mu i)]$ are positive. The graph of this quadratic equation of $n$ in the first and forth quadrants of the $n-f$ coordinates is a convex curve cutting the vertical axis above the horizontal axis since $f(0)=D>0, f^{\prime}(0)=-B<0, f^{\prime \prime}(n)=2 A>0$. The unique minimum point $n=B / 2 A>0$ of this curve is given by $f^{\prime}(n)=0$. Hence, this curve may have two cutting points of the right half horizontal axis, which means two equilibria, given

The market clearing condition for labor is not independent of (9) and (10) according to Walras' law. Hence, it can be used to check if the algebra is correct. Indeed, inserting the equilibrium values of the endogenous variables and transaction costs in terms of labor into this market clearing condition for labor confirms that it is the same as (9). 
by $f\left(n^{*}\right)=0$. Call the two solutions of $f(n)=0 n_{1}$ and $n_{2}$, respectively, and assume $n_{2}>n_{1}$. Hence, we can see that $f^{\prime}\left(n_{1}\right)<0$ and $f^{\prime}\left(n_{2}\right)>0$ for a convex curve with the unique minimum point that is below the horizontal axis. But we can show that for a positive income, $\partial f / \partial n=(\alpha / n)[1-b /(1-\mu i)]\left(0.5 \gamma n^{2}-L\right)<0$ must hold when the first order condition (11) holds since positive income in (9) requires $1-b /(1-\mu i)>$ 0 and $0.5 \gamma n^{2}-L<0$. This implies that $n_{2}$ cannot be an equilibrium. We have then established the claim that there is only one equilibrium in this model. ${ }^{3}$

Differentiating (11) and using the implicit function theorem, we can identify the comparative statics of the equilibrium number of active modern firms.

$$
\begin{gathered}
d n / d L=-(\partial f / \partial L) /(\partial f / \partial n)>0, \quad d n / d \mu=-(\partial f / \partial \mu) /(\partial f / \partial n)<0, \\
d n / d b=-(\partial f / \partial b) /(\partial f / \partial n)<0, \quad d n / d i=-(\partial f / \partial i) /(\partial f / \partial n)<0 .
\end{gathered}
$$

where $\partial f / \partial n=(\alpha / n)[1-b /(1-\mu i)]\left(0.5 \gamma n^{2}-L\right)<0$ if (11) holds and $\partial f / \partial \gamma<0$ if (11) holds, $\partial f / \partial b, \partial f / \partial i, \partial f / \partial \mu<0, \partial f / \partial L>0$. (12) implies that there is substitution between trading efficiency and population size in promoting industrialization. For a given $\mu$, a larger population size generates a higher degree of industrialization. For a given $L$, better general transaction conditions generate a higher degree of industrialization. $d n / d i<0$ implies that the degree of industrialization is lower for a country with the larger transaction cost coefficient which implies a larger $i$. This implies that a large country may have low degree of industrialization if its transaction conditions are very bad.

\section{B. General Equilibrium and Comparative Statics}

The general equilibrium in country $i$ is summarized as follows.

$$
\begin{gathered}
p_{X}=1, \quad p_{z}=1 / \theta \quad L_{\mathrm{z}}=(1-\alpha)(\Pi+L), \\
X^{d}=\alpha(\Pi+L) / m, Z=(1-\alpha) \theta(\Pi+L) \\
L_{\mathrm{x}}=\int_{0}{ }_{0}\{[b \alpha(\Pi+L) /(1-c) m]+\gamma j\} d j=[b \alpha(\Pi+L) n /(1-c) m]+0.5 \gamma n^{2} \\
R \equiv L_{\mathrm{x}} / L, U=m^{\alpha(1-\rho) / \rho} \alpha^{\alpha}[\theta(1-\alpha)]^{1-\alpha}[(\Pi / L)+1] \\
(\Pi / L)+1=\gamma m n(1-\mu i) / \alpha(1-b-\mu i) L, \text { and }
\end{gathered}
$$

$n$ is given by (11),

where $U$ is per capita real income (equilibrium utility level), $(\Pi / L)+1$ is per capita

\footnotetext{
${ }^{3}$ Multiplicity of equilibria is discussed in Murphy, Shleifer, and Vishny (1989).
} 
income in terms of labor, $L_{x}$ is the amount of labor allocated to all active modern firms, and $R \equiv L_{\mathrm{x}} / L$ represents the relative work force in the modern and traditional sectors. Differentiating $U$ in (13) and using (11) and (12), it can be shown that

$$
\begin{gathered}
d U / d L>0, \text { and } d U / d \mu<0, d R / d L>0, d R / d \mu<0, \\
d n / d L>0, d n / d \mu<0, d n / d b<0, \\
d(m-n) / d L=-d n / d L<0, d(m-n) / d \mu=-d n / d \mu>0 .
\end{gathered}
$$

It is straightforward that the number of active traditional sectors $m-n$ decreases as the population size increases and/or as transaction conditions are improved. Hence, duality of economic structure is endogenized.

The comparative statics can be summarized in the following proposition.

Proposition 1: As population size increases and/or as general transaction conditions are improved, the equilibrium number of active modern sectors, relative population size of modern and traditional sectors, degree of capital intensity of active modern firms, productivity, and per capita real income increase. For a given general transaction condition and population size, the country with more favorable country specific transportation conditions has higher degree of industrialization than in other countries.

Suppose general transaction conditions are very bad in the initial time. Then no modern firm operates in any country. As time goes by, general transaction conditions are improved, so that some modern firms operate in the country with the smallest transaction cost coefficient $c_{0}=s$. But other countries are not industrialized. As general transaction conditions are further improved, those countries with slightly larger transaction cost coefficient start industrializing and the number of active modern firms in each of the industrializing countries increases. As general transaction conditions are further improved, those countries with the largest transaction cost coefficients are eventually industrialized. This process goes on until all countries and all sectors in each country are industrialized.

\section{Extension and Applications}

In the industrialization process described in the preceding section, each less developed country gradually duplicates the industrialization in the relatively more developed country in the absence of international trade. This looks like that each 
less developed country carries out import substitution strategy and relies on domestic market for industrialization. Because of positive effect of population size on industrialization, as shown in (14), we can extend our model to the analysis of international trade and export oriented industrialization. The opening up of international trade will increase the population size in the integrated world market, thereby promoting industrialization and economic development. But in our model transaction costs counteract unlimited expansion of international trade. Hence, the degree of market integration can be endogenized using the trade off between economies of scale and transaction costs.

Suppose a continuum of countries with mass $M$ are divided between the set of developed countries with mass $N$ and the set of underdeveloped countries with mass $M-N$. We now interpret $L$ in (13) and (14) as the total population size in the $N$ developed countries. In each of the $N$ countries, some modern sectors operate and sell their produce to domestic as well as the world market. The dividing line between the developed world and the underdeveloped world is endogenously determined by the condition that in a marginal country between the two worlds the least capital-intensive modern sector has non-positive profit. This implies that in this country all modern sectors which cannot have more profit than the least capital-intensive sector, will not operate in equilibrium. Recall that countries are indexed according to their country specific trading efficiencies. Country 0 has the smallest country specific transaction cost coefficient $c_{0}=s$ and country $M$ has the largest transaction cost coefficient $c_{M}=\mu M$. The transaction cost coefficient for the marginal country $N, c_{N}=\mu N$ is in between the two extremes. This implies that for all countries $i>N$, profit for each modern sector is negative. Hence, in each of the $M-N$ less-developed countries with low trading efficiencies, only traditional firms operate. Since productivity and therefore price of goods produced by the traditional sectors are independent of the size of the firm, the productivity and prices in the traditional sectors are independent of the extent of the market. We assume that international trade of cottage firms' produce involves infinitesimally transaction cost although domestic trade of their produce involves no transaction cost. Then, when no modern firm operates, firms and consumers have no incentive to participate in international trade. But if some modern firms operate, then international trade can increase the extent of the market and more economies of scale can be exploited at the cost of transportation of goods. This assumption will ensure that each less developed country will endogenously choose autarky, where 
all goods are self-provided by local cottage firms, in equilibrium. ${ }^{4}$

The dividing line between the developed countries and the underdeveloped countries is given by the zero profit condition for the active modern sector with the smallest fixed cost in the marginal $N$-th country. This implies that profit in all other modern sectors with larger fixed cost in this country are negative. Also profit in all modern sectors in $M-N$ less developed countries which have larger transaction cost coefficients than the marginal country are negative. This zero profit condition is

$$
\pi_{N 0}=(1-\mu N-b) x_{j}-\delta=0
$$

where $\delta$ is the smallest fixed cost in the modern sector producing good 0 and $x_{j}$ is the total output of this good in the integrated world market consisting of $N$ developed countries.

Now, the zero profit condition for the marginal firm in the integrated developed world can be obtained by assuming the profit in $n$-th modern sector in country 0 , which has the smallest transaction cost coefficient $c_{0}=s$, to be zero. If this firm cannot break even in the marginal sector which has the largest fixed cost among all active modern sectors, the other countries with larger transaction cost coefficients than country 0 cannot possibly break even in this sector. This zero profit condition is

$$
\pi_{0 n}=(1-s-b) x_{j}-\gamma n=0 \text {. }
$$

The number of active modern sectors $n$ in the integrated developed world is endogenously determined by this equation.

The general equilibrium in the extended model consists of several components. The first of them is a local equilibrium in the integrated developed world with $N$ countries. Interpreting $L$ in (9) as the population size in the integrated market with $N$ developed countries, (9), (15), and (16) determine the equilibrium $n$ in the developed world in the extended model. Using (15) and (16) to eliminate the total market demand $x_{j}$, which must be the same for all industrial goods, we can identify the connection between the network size of internationa9 trade $N$ and the number

\footnotetext{
${ }^{4}$ We need the assumption that migration from the less developed countries to the developed ones is prohibitively expensive. Otherwise, all individuals in the less developed countries will migrate to the developed countries which have better transaction condition. Also, we need the assumption that all individuals in the developed countries can freely migrate between countries and they equally share ownership of all active modern firms. The two assumptions are quite ad hoc. But they are essential for keeping the extended model tractable.
} 
of active modern sectors in the integrated developed world, $n$.

$$
\begin{gathered}
N=[(1-b)(1-s) n-\delta(1-b-s)] /[(1-s) n-\delta(1-b-s)] \mu, \\
d N / d \mu=(\partial N / \partial \mu)+(\partial N / \partial n)(d n / d \mu)<0
\end{gathered}
$$

where $\partial N / \partial \mu<0, \partial N / \partial n>0$, and $d n / d \mu<0$ due to (12). Beside (17), the rest of comparative statics of the local equilibrium is the same as in (14).

The local autarky equilibrium in each of the $M-N$ less developed countries is a component of the general equilibrium. In each of the countries all industrial goods are supplied by traditional (or cottage, handcraft) sectors. Because of the assumption that domestic trade of goods produced by cottage firms involve no transaction costs, the difference in transaction cost coefficient for trade of goods produced by modern sectors between countries will not generate difference in per capita real income between less developed countries. Therefore, per capita income is the same in all less developed countries, lower than in the developed countries. The autarky equilibrium for each of those countries is

$$
\begin{gathered}
p_{z}=1 / \theta, \quad p_{x}=1, \quad X=\alpha L_{i} / m, \quad Z=(1-\alpha) \theta L_{i} \\
U=m^{\alpha(1-\rho) / \rho} \alpha^{\alpha}[\theta(1-\alpha)]^{1-\alpha}
\end{gathered}
$$

where $L_{i}$ is the population size of country $i \in(N, M]$. We now assume that in the initial period $\mu$ is so large that $c_{i}=\mu i$ is too large for any modern firm to break even in all countries $i>0$. Hence, only country 0 (the UK) has modern sectors. As time goes by, $\mu$ decreases, the scope for trading off economies of scale against transaction costs is enlarged, so that the modern sectors with low fixed cost (low capital intensity) become profitable, this increases income and thereby demand, which makes more modern firms become profitable. This higher degree of industrialization in the developed world makes more of less developed countries be willing to use international trade to exploit economies of scale, which extends overseas market for domestic produce in the developed countries, which in turns attracts more participants of the network of trade. But increased transaction costs counteract the positive feedback between the extent of the market and economies of scale that can be exploited and between the number of countries involved in international trade and gains from trade. A new equilibrium is established that balances the trade off between economies of scale and transaction costs. Those countries with larger transaction cost coefficients and those modern sectors that 
are more capital intensive are not involved in international trade in the early stage of world development.

As general transaction conditions are further improved, the equilibrium number (measure) of modern sectors $n$ and the number (measure) of countries involved in industrialization and international trade, $N$, increase. The newly industrializing countries produce and export goods of low capital intensity and those old industrialized countries produce and export capital intensive goods. This process continues until the most capital intensive sectors are produced by the modern sector and all countries are involved in the integrated world market. This is what happened in the Western Europe in the $18^{\text {th }}$ and $19^{\text {th }}$ century. Figure 1 gives an intuitive illustration of this spread of market led industrialization.

\section{A. Two Types of Dual Structure}

Our model endogenizes not only duality between modern and traditional sectors, but also duality between the developed and underdeveloped worlds. As worldwide transaction conditions are improved ( $\mu$ decreases) or population size increases, the comparative statics indicate that per capita income increases for the developed countries involved in international trade, but per capita income in the less developed countries which are still left out of the world market does not change. Hence, inequality of per capita income between the developed and less developed countries increases. This inequality decreases as the last less developed country jumps into the world market.

Figure 1, together with (13) and (17), captures a general equilibrium mechanism that entails circular causation: each modern firm's profit and thereby its decision of being active is determined by the network size of industrial linkages and trade flows (or the thickness of the market), while the network size is determined by all firms' decisions on whether they participate in this industrialization process. Each country's decision of being involved in the world market is dependent not only on the size of the world market, $N$, but also on the degree of industrialization, $n$, in the developed world, while the degree of industrialization and the network size of international trade is determined by all countries' decisions on whether they participate in this networking process. Our model shows that the notion of general equilibrium (fixed point) is a powerful vehicle for figuring out the networking mechanism in a decentralized market. This is the essence of the idea of market led and "unbalanced" industrialization: the market plays a sophisticated function in networking self-interested participants of the network of industrial linkages and 
Figure 1. Map of Industrialization in Europe in $18^{\text {th }}$ and $19^{\text {th }}$ Centuries

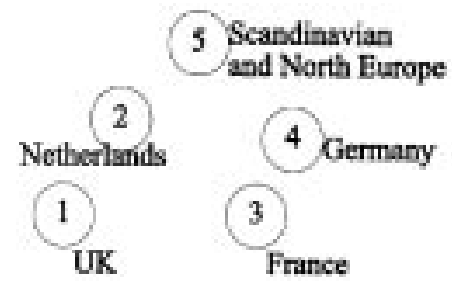

South 6

(a) UK started industrialization in 1760
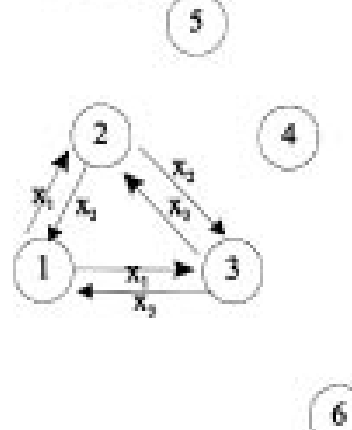

(c) France started industrialization in 1815

6
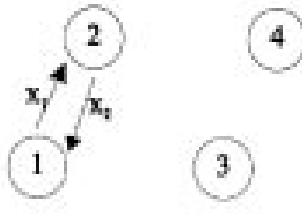

3

(b) Netherlands started

industrialization in 1790

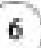

5
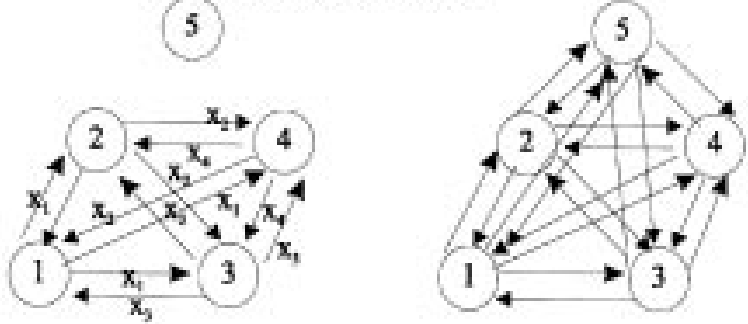

6

(d) Germany started industrialization in 1860

trade flows when all participants may not understand this function.

\section{B. Import Substitution Versus Export Oriented Industrialization}

The import substitution strategy that was advocated by some development economists after the WWII is like the industrialization process in the absence of international trade, described in (13) and (14). ${ }^{5}$ The networking process of international trade and industrialization described in the extended model with $M$ countries is consistent with export oriented industrialization. Suppose a developed country (UK) has a small transaction cost coefficient, so that it runs many modern sectors profitably. A less developed country has very large transaction cost coefficient, so that its modern sectors are not profitable. As general transaction

\footnotetext{
${ }^{5}$ See, for instance, Balassa (1980), Chenery, Robinson, and Syrquin (1986), Meier (1989, pp.297-306), and Bruton (1998) for discussion of development strategies.
} 
conditions are improved in all countries (due to commercialized production of steam engines or automobiles), some modern sectors become marginally profitable in the less developed country. Hence, it can start import substitution industrialization. The import substitution strategy works to the degree that as $\mu$ decreases, less developed countries will start industrializing one by one in the absence of international trade of industrial goods. But the import substitution strategy artificially increases transaction cost coefficient $c_{i}$ by imposing high tariffs, thereby missing faster industrialization that can be generated by expansion of the network size of the world market. Hence, it is inferior to export oriented industrialization, which uses tariff reduction and free trade zone to reduce transaction cost coefficient $c$.

The results of the extended model are summarized in the following proposition.

Proposition 2: As transaction conditions are improved, and/or as the population size increases, the following development phenomena concur. The equilibrium dividing line between the developed world and less developed world moves in the direction that more less-developed and self-sufficient countries are involved in the integrated developed world. In the developed world, the number of operating modern firms, per capita income, and trade dependence increase. In this process inequality of income distribution increases as dual structure emerges from the transitional stage and then declines as the dual structure disappears. The countries with better transaction conditions are involved in international trade before other countries are.

If we use the zero profit conditions in all active modern sectors to determine the prices of their produce, we can then express the representative consumer's utility as a function of the degree of industrialization, $n$. Maximizing the utility with respect to $n$ yields the Pareto optimum degree of industrialization which is higher than the equilibrium one. This is because the price mechanism fails to transmit information of the production and transaction conditions of the modern firms to consumers. In other words, consumers receive benefit of industrialization via dividend earnings, but they allocate the same share of dividend earnings to buy a good produced by a modern or a cottage firm because of the misinformation of price signals. In the Pareto optimum, each consumer consumes more of produce of each modern sector than that of each cottage sector. Slight differentiation between a good produced by the cottage firm and that by the modern firm will eliminate the distortions. But we will go to the regime of monopolistic competition which causes another type of distortion. 


\section{Concluding Remarks}

This paper introduces the trade off between economies of scale and transaction costs into the MSV model to endogenize the number of modern sectors. We have developed an approach to analyzing the MSV model by specifying the zero profit condition for a marginal modern firm and keeping the original flavor of the MSV model which is the feedback loop between positive dividend earning, the extent of the market, and economies of scale that can be exploited. However, as transaction costs are introduced, big push industrialization will not occur unless transaction conditions have a sudden big improvement. Our model predicts a gradual spread of industrialization from the countries with better transaction conditions to other less developed countries, as general transaction conditions are improved. In this process inequality of income between the developed and less developed countries increases as a dual structure emerges and finally decreases as the dual structure disappears eventually. Also, the number of modern sectors increases, the degree of trade dependence increases, productivity of the industrial sector increases, per capita income increases, the degree of market integration increases, and the number of traditional sectors decreases.

This model formalizes the idea of unbalanced and market led industrialization. Our model suggests that the feedback loop between dividend earning (based on private property rights to residual returns of firms), the extent of the market, and economies of scale that can be exploited is essential for successful industrialization though the networking function of the market is not perfect.

\section{Acknowledgement}

We are grateful to Francisco Rodriguez for stimulating discussion and to the participants of the seminar at the Harvard Center for International Development and of 1999 Conference of Development Economics for comments. Also, comments from an anonymous referee are appreciated. We are solely responsible for the remaining errors.

Date accepted: July, 2001 


\section{References}

Balassa, Bela (1989), “Outward Orientation”, in H. Chenery and T.N. Srinivasan (eds), Handbook of Development Economics, Amsterdam: North-Holland, vol. II, pp. 164590.

Barro, R. (1997), Determinants of Economic Growth, Cambridge, MA, MIT Press.

Baechler, Jean (1976), The Origins of Capitalism, Translated by Barr Cooper, Oxford, Blackwell.

Bruton, Henry (1998), “A Reconsideration of Import Substitution”, Journal of Economic Literature, 36, 903-36.

Chenery, Robinson, and Syrquin, eds. (1986), Industrialization and Growth: A Comparative Studies, New York, Oxford University Press.

Dasgupta, Partha (1995), "The Population Problem: Theory and Evidence", Journal of Economic Literature, 33, 1879-1902.

Easton, Stephen and Michael, Walker (1997): "Income, Growth, and Economic Freedom”, American Economic Review, Papers and Proceedings, 87, 328-32.

Fleming, Marcus (1955), "External Economies and the Doctrine of Balanced Growth", Economic Journal, 65, 241-56.

Frye, Timothy and Shleifer, Andrei (1997): “The Invisible Hand and the Grabbing Hand”. American Economic Review, Papers and Proceedings, 87, 354-58.

Gallup, John and Jeff Sachs (1998), "Geography and Economic Development", Working Paper, Harvard Institute for International Development.

Hart, O. (1995), Firms, Contracts, and Financial Structure. Oxford, Clarendon Press.

Hirschman, Albert (1958), The Strategy of Economic Development, New Haven, Yale University Press.

Holmstrom, Bengt and John Roberts (1998), "The Boundaries of the Firm Revisited", Journal of Economic Perspectives, 12, 73-94.

Kelly, Morgan (1997): “The Dynamics of Smithian Growth". Quarterly Journal of Economics, 112, 939-64.

Krugman, Paul (1995), Development, Geography, and Economic Theory, Cambridge, MIT Press.

Krugman, P. And Venables, A.J. (1995), "Globalization and the Inequality of Nations", Quarterly Journal of Economics, 110, 857-80.

Meier, G. (1989), Leading Issues in Economic Development, New York, Oxford University Press.

Milgrom, P. and Roberts, J. (1992), Economics, Organization and Management, Englewood Cliffs, Prentice-Hall.

Mises, L. (1922), Socialism: An Economic and Sociological Analysis, Indianapolis: Liberty Classics, reprinted in 1981.

Mokyr, Joel (1990) The Lever of Richs: Technological Creativity and Economic Progress, New York, Oxford University Press. 
Mokyr, Joel (1993) (ed.) The British Industrial Revolution, An Economic Perspective, Boulder, Westview Press.

Murphy, K., Shleifer, A., and Vishny, R. (1989): "Industrialization and the Big Push," Journal of Political Economy, 97: 1003-26.

National Research Council (1986), Population Growth and Economic Development: Policy Questions. Washington, DC, National Academy of Sciences Press.

North, Douglas, (1981) Structure and Change in Economic History, New York, Norton. North, Douglass and Weingast, Barry (1989), "Consititutions and Commitment: The Evolution of Institutions Governing Public Choice in Seventeenth-Century England", Journal of Economic History, XLIX, pp 803-32.

Nurske, R. (1953), Problems of Capital Formation in Underdeveloped Countries, New York, Oxford University Press

Rosen, S. (1983), "Specialization and Human Capital", Journal of Labor Economics, 1, 43-49.

Rosenstein-Rodam, P. (1943), Problems of industrialization in Eastern and Southeastern Europe, Economic Journal, June-September issue.

Sachs, J. (1996), "Notes on the Life Cycle of State-led Industrilization", Japan and the World Economy. 8, 153-74.

Sachs, J. and Woo (1993), "Structural Factors in the Economic Reforms of China, Eastern

Europe and the Former Soviet Union." Working Paper, Harvard University, Department of Economics.

Sachs, J. and Warner, A. (1995) "Economic Reform and the Process of Global Integration," Brookings Papers on Economic Activity, 1.

Sachs, Jeffrey and Warner, Andrew (1997): "Fundamental Sources of Long-Run Growth." American Economic Review, Papers and Proceedings, 87, 184-88.

Sheahan, J. (1958), "International Specialization and the Concept of Balanced Growth," Quarterly Journal of Economics, 52, 183-97.

Shi, H. and X. Yang (1995), “A New Theory of Industrialization”, Journal of Comparative Economics, 20, 171-89.

Shi, H. and X. Yang (1998), "Centralised Hierarchy within a Firm vs. Decentralised Hierarchy in the Market", in K. Arrow, Y-K. Ng, and X. Yang eds. Increasing Returns and Economic Analysis, London, Macmillan.

Stigler, G. (1951), "The Division of Labor is Limited by the Extent of the Market", Journal of Political Economy, 59, 185-93.

Sun, G. and Lio, M. (1997): "A General Equilibrium Model Endogenizing the Level of Division of Labor and Variety of Producer Goods", Working Paper, Department of Economics, Monash University.

Yang, X. and S. Ng (1998), "Specialization and Division of Labor: a Survey," K. Arrow et al. (ed.), Increasing Returns and Economic Analysis, London, Macmillan.

Young, Allyn (1928), "Increasing Returns and Economic Progress", The Economic Journal, 38, 527-42. 